\title{
Medication reconciliation in orthopedic and neurological patients in a public hospital
}

\author{
Cássia Regina EIDELWEIN ${ }^{1}$ (D), Andréia Cristina SANCHES ${ }^{1}$ (D) , Luciane de Fátima CALDEIRA ${ }^{1}$ (D) \\ ${ }^{1}$ Universidade Estadual do Oeste do Paraná/Hospital Universitário do Oeste do Paraná \\ Corresponding author: Eidelwein CR, cassiareginae@gmail.com \\ Submitted: 29-01-2019 Resubmitted: 06-07-2020 Accepted: 06-07-2020 \\ Peer review: blind reviewers
}

\begin{abstract}
Objective: To evaluate the discrepancies found by the clinical pharmacy service during medication reconciliations in patients hospitalized for orthopedics and neurology in a university hospital. Methods: A cross-sectional, descriptive and retrospective study was carried out from January to June 2018 with the patients followed-up by the clinical pharmacy service (orthopedics and neurology). Data was collected through medical charts and pharmacotherapeutic follow-up forms. The differences between the list of medications that the patient was using at home and the prescription from the hospital was classified as a discrepancy (justified or unjustified). Medical acceptance of the pharmaceutical interventions was assessed. The medications involved in the discrepancies were classified according to the ATC classification in its $1^{\text {st }}$ level. Descriptive statistics was performed using the Excel program and Pearson's chi-square test. Results: Of the 939 medications used by the patients, 673 (71.7\%) presented discrepancies and in 371 (55.1\%), unjustified discrepancies were found. Of the 507 patients included in the study, 154 (30.4\%) presented at least one medication error. In 96.8\% of the cases, the pharmaceutical interventions were performed, and acceptability was 30.6\%, avoiding 110 errors. Medication omission was the most common type of discrepancy and the medical group most frequently involved was the cardiovascular system. Conclusions: Medication errors in admission to the orthopedics and neurology sectors are frequent, but they can be identified and solved through medication reconciliation, with professional clinical pharmacists able to perform it, collaborating for the safety of the patients.
\end{abstract}

Keywords: medication errors, patient safety, drug prescriptions, medication reconciliation.

\section{Conciliação de medicamentos em pacientes ortopédicos e neurológicos em um hospital público}

\begin{abstract}
Resumo
Objetivo: Avaliar as discrepâncias encontradas pelo serviço de farmácia clínica durante a realização de conciliação de medicamentos de pacientes internados pela ortopedia e neurologia em um hospital universitário. Métodos: Foi realizado um estudo transversal, descritivo e de caráter retrospectivo, incluindo-se os pacientes acompanhados pelo serviço de farmácia clínica (ortopedia e neurologia) no período de janeiro a junho de 2018. Os dados foram coletados pelos prontuários e formulários de acompanhamento farmacoterapêutico. As diferenças entre a lista de medicamentos que o paciente fazia uso em seu domicílio e a prescrição hospitalar foi classificada como discrepância (justificada ou não justificada). Foi avaliado o aceite médico das intervenções farmacêuticas. Os medicamentos envolvidos nas discrepâncias foram classificados de acordo com a classificação ATC em seu 1o nível. Foi realizada estatística descritiva através do programa Excel e teste qui-quadrado de Pearson. Resultados: Dos 939 medicamentos em uso pelos pacientes, 673 (71,7\%) apresentavam discrepância e em 371 (55,1\%) foram encontrados discrepâncias não justificadas. Apresentavam pelo menos um erro de medicação, $154(30,4 \%)$ dos 507 pacientes incluídos no estudo. Em 96,8\% dos casos, as intervenções farmacêuticas foram realizadas, com aceitação de 30,6\%, evitando-se 110 erros. A omissão de medicamentos foi o tipo de discrepância mais comum e o grupo medicamentoso mais frequentemente envolvido foi o aparelho cardiovascular. Conclusões: Os erros de medicação na admissão nos setores de ortopedia e neurologia são frequentes, mas podem ser identificados e resolvidos por meio da conciliação de medicamentos, sendo os farmacêuticos clínicos, profissionais aptos a realiza-la, colaborando na segurança dos pacientes.
\end{abstract}

Palavras-chave: erros de medicação, segurança do paciente, prescrições de medicamentos, reconciliação de medicamentos. 


\section{Introduction}

Medication reconciliation can be described as a process that consists of obtaining a complete, accurate, and up-to-date list of medications used by each patient outside the hospital (including name, dosage, frequency, and route of administration) and analyzed against medical prescriptions made at admission, transfer, outpatient consultations, and hospital discharge ${ }^{1}$.

More advanced medication reconciliation involves interprofessional collaboration (for example, a physician and nurse or a pharmacist conducting team medication reconciliation), integration into discharge summaries and prescriptions, and provision of medication advice to the patients ${ }^{2}$. The pharmaceutical professional is qualified to collect data on the drugs used by the patient and to promote efforts in order to establish an effective drug treatment through the process of reconciling medications by participating in patient care together with the multidisciplinary team, thus improving the safety of hospitalized patients.

A number of studies reveal that medication reconciliation has a direct impact on the prevention of adverse events related to medications, being effective in reducing the discrepancies identified, thus generating a reduction of this type of medication error by about $70 \%^{3}$. Thus, it is a service that aims to reduce medication errors such as duplications or omissions, avoiding unnecessary harms, potential risks, and costs in patient care $\mathrm{c}^{4}$.

Medication errors are more common in the transition periods the patient's treatment, with the incorrect or incomplete transfer of information being the main cause of errors in these conditions ${ }^{5}$. Obtaining inaccurate medication history data at hospital admission can lead to non-conformities in drug therapy during hospitalization and therapeutic failure, thus compromising patient safety ${ }^{6}$.

It is estimated that approximately $60 \%$ of the hospitalized patients have one or more discrepancies in their medication history at admission ${ }^{7}$. According to Pippins et al. ${ }^{8}$, discrepancy is defined as any difference between the list of drugs that the patients use at their homes and the hospital prescription. Discrepancies can be justified or unjustified, and the latter are considered medication errors ${ }^{9}$. Medication reconciliation is a strategy to reduce the occurrence of drug discrepancies that can lead to adverse drug events ${ }^{5}$.

In view of the above, the present study aimed to describe the discrepancies identified by the clinical pharmacy service in performing medication reconciliations of patients hospitalized in orthopedics and neurology, as well as to evaluate the acceptance of pharmaceutical interventions by the medical team in a university hospital.

\section{Methods}

This is a cross-sectional, descriptive and retrospective study, carried out in a general and public hospital with 195 beds. The medical records and forms of pharmacotherapeutic follow-up of the patients interviewed by the clinical pharmacy service, assisted by orthopedics and neurology admitted to the G2 Emergency Orthopedics and G3 - Orthopedics/Neurology wards, were evaluated from January to June 2018. According to the performance criteria of the clinical pharmacy service, patients under the age of 18 were not interviewed, as well as those who had spent time in the intensive care unit and/or emergency room, patients in respiratory isolation, non-contact patients, and those without a companion or not found due to discharge.

Information related to the medication history was collected, considering the following as potential sources: patient, family member/caregiver, medication bag, medical prescription, and information contained in the electronic medical record.

The pharmaceutical interviews were carried out at the bedside, and the medical prescription on the day of the interview was then compared to the list of medications that the patient used before hospital admission. From this comparison, discrepancies were identified, which were classified as justified and unjustified, as well as to the type of alteration performed by the physician.

The assessment of discrepancies was adapted to the reality of the hospital, following what was proposed by Gleason et al. ${ }^{10}$ and by Lombardi et al. ${ }^{11}$. These were classified as unjustified and justified. Those that occurred when the physician unintentionally added, altered or omitted a medication that the patient was using before the care transition were called unjustified, which are subdivided into: error by omission, error by action (the medication was not in use before hospitalization), dose error, error in route of administration, error in frequency of use, different medication (the medication different from what was being used before hospitalization), and dosage error (dose and frequency together).

Justified discrepancies are those in which there was an explanation for the non-prescription and/or alteration of the medication. They were subdivided according to some aspects: clinical protocol, pharmacological alteration-different medication/route/dose/ frequency, non-standard medication (such as substitution for a standardized alternative in the institution), and clinical decision not to prescribe.

The discrepancy was assessed by the pharmacist and, when unjustified discrepancies were identified, verbal interventions were made with the responsible physician, as well as a follow-up in the electronic medical record, suggesting medication reconciliation in the hospital prescription. When the interventions were not accepted within 24 hours, this procedure was repeated. They were considered accepted when the physician changed the prescription within 48 hours after the first pharmaceutical intervention. The data were recorded on an individual pharmacotherapeutic followup form, with data being collected through these records.

The therapeutic class of the drugs involved in the discrepancies was classified according to the Anatomical Therapeutic Chemical (ATC) classification according to the major systemic groups $\left(1^{\text {st }}\right.$ level) $)^{12}$

The variables studied were number of discrepancies identified, types of discrepancies, therapeutic classes involved, number of reconciled medications, pharmaceutical interventions performed, and accepted interventions. Sociodemographic variables were also evaluated, such as gender and age, as well as data related to the patient's health and hospitalization: length of stay, medical specialty, previous diseases, and history of medications prior to hospitalization. The collected data were organized in Excel spreadsheets and evaluated using descriptive statistics. The comparison between the groups was performed in the Action function of the Excel program, using Pearson's chi-square test, and was considered significant when $p<0.05$.

The study was approved by the Research Ethics Committee of the State University of Western Paraná, through opinion No. $1,872,685$. 


\section{Results}

During the study period, 507 patients were followed up, the characteristics of age, gender, specialty, days of hospitalization, and previous diseases are shown in Table 1 . The number of previous diseases reported was 537, with only 266 (52.5\%) patients having at least one previous disease. It can be seen that the most common diseases were related to the cardiovascular and endocrinology specialties.

Regarding the sources of information used to collect the medication history, the data contained in electronic medical records was collected in all cases. Still, in 398 (78.5\%) cases, the patients were consulted. In 61 (12\%) only the relative/caregiver was consulted, as the patient was not responsive at the time of the interview. In 40 (7.9\%) patients, in addition to the individuals interviewed and the data in the medical records, there were more sources of information, such as a medication bag and a medical prescription that the patient had taken to the hospital. The medical records were evaluated only in $8(1.6 \%)$ situations.

Of the evaluated patients, 143 (28.2\%) presented at least one justified discrepancy, totaling 302 records. 371 unjustified discrepancies were identified in 154 evaluated patients (30.4\%), corresponding to a mean of $2.4 \pm 1.9$ unjustified discrepancies per patient with this type of discrepancy, being considered medication errors. Of these, $58(37.7 \%)$ presented an unjustified discrepancy and $96(62.3 \%)$, two or more unjustified discrepancies, this difference being statistically significant $(p=0.002)$ (Table 1$)$.

Table 1. Characteristics of the study subjects, Cascavel/PR 2018.

\begin{tabular}{|c|c|}
\hline Characteristics & $\begin{array}{c}\text { All } \\
\mathrm{N}=507\end{array}$ \\
\hline Age (years old) Mean+SD ${ }^{1}$ & $51.5 \pm 20.1$ \\
\hline Hospitalization (days) Mean+SD ${ }^{1}$ & $7.2 \pm 8.9$ \\
\hline Male gender $\mathbf{n}(\%)$ & $291(57.4)$ \\
\hline \multicolumn{2}{|l|}{ Specialty } \\
\hline Orthopedics & $355(70.0)$ \\
\hline Neurology & $152(30.0)$ \\
\hline Clinical conditions of the patients $n(\%)$ & $N=537$ \\
\hline Cardiovascular & $213(39.7)$ \\
\hline Endocrinology & $144(26.8)$ \\
\hline Neurology & $46(8.6)$ \\
\hline Psychiatry & $36(6.7)$ \\
\hline Rheumatology & $20(3.7)$ \\
\hline Oncology & $15(2.8)$ \\
\hline Pneumology & $14(2.8)$ \\
\hline Gastroenterology & $11(2.0)$ \\
\hline Nephrology & $8(1.5)$ \\
\hline Vascular & $7(1.3)$ \\
\hline Hepatology & $4(0.7)$ \\
\hline Infectology & $4(0.7)$ \\
\hline Hematology & $3(0.6)$ \\
\hline Otolaryngology & $3(0.6)$ \\
\hline Urology & $3(0.6)$ \\
\hline Dermatology & $2(0.4)$ \\
\hline Ophthalmology & $2(0.4)$ \\
\hline Gynecology & $1(0.2)$ \\
\hline
\end{tabular}

${ }^{1} \mathrm{SD}$ : Standard Deviation; ${ }^{2}$ Dichotomous variable only described in one of the categories.
The description of the discrepancies is shown in Table 2, as well as the medications involved according to the major groups of the chemical therapeutic anatomical classification (ATC) system.

939 home-use medications were accounted for by 272 (53.6\%) patients. Of these, $673(71.7 \%)$ had discrepancies. A greater occurrence of errors by default can be observed. The most frequent drugs in the discrepancies were those of the cardiovascular system group.

The number of pharmaceutical interventions carried out on unjustified discrepancies was 359 (96.8\%) and not performed, 12 (3.2\%). The acceptance of the interventions is also specified in Table 2.

\section{Discussion}

The medication reconciliation process has been consolidated as a strategy to reduce medication errors, potential risks to patients and costs. It is a tool recommended by the World Health Organization (WHO) and health service quality certifiers in several countries to ensure patient safety ${ }^{13}$. To that end, the clinical pharmacy service at the Western Paraná University Hospital implemented the medication reconciliation process in the orthopedics and neurology units in 2013.

It can be seen that the patients included in this study had a mean age, similar to the mean age found in a study carried out by Lombardi et al. ${ }^{11}$ in a hospital in the state of Paraná, which presented a mean of 59 years old (SD \pm 6 years old) and also in a study conducted by Nascimento ${ }^{14}$ where he found a mean age of 54.75 years old (SD \pm 18.5 years old).

Regarding gender, it was possible to observe a higher frequency of males; a similar result was found in a study carried out in a cardiology unit of a large hospital, with $53.29 \%$ of male patients ${ }^{15}$. This result is divergent when compared to other studies in the literature that found more female individuals ${ }^{11,14,16}$.

Among the neurology and orthopedics patients, they were mostly admitted by the orthopedics specialty, and the patients in this specialty had higher turnover and shorter hospital stay, in addition to the hospital in question being a reference in the region for treating trauma.

With regard to the presence of previous diseases, a study by Domingos ${ }^{17}$ in an orthotraumatology ward of a hospital in Portugal reported results similar to this study regarding the main types of diseases presented by the patients. A number of Brazilian studies have also shown similar results regarding the higher prevalence of cardiovascular and endocrine diseases ${ }^{14,18,19}$.

During the interviews, the patients or their companions provided information about the drugs they most used at their homes, proving that they have an essential role in the reconciliation process ${ }^{3}$.

Discrepancies in medication can cause harms related both to the effectiveness and safety of the drug therapy. In this study, more unjustified discrepancies were observed, and these are also commonly observed in other studies ${ }^{17,19,20}$. A systematic review conducted by Tam et al. ${ }^{21}$ showed that up to $67 \%$ of the patients admitted to the hospital have unjustified drug discrepancies. 
Table 2. Results of medication reconciliation, cascavel/pr, 2018.

\begin{tabular}{|c|c|c|c|}
\hline \multirow[b]{2}{*}{ Information } & \multirow{2}{*}{$\begin{array}{c}\text { Total } \\
\mathrm{N}=673\end{array}$} & \multicolumn{2}{|c|}{ Discrepancies } \\
\hline & & $\begin{array}{c}\text { Justified } \\
N=302\end{array}$ & $\begin{array}{l}\text { Unjustified } \\
\qquad N=371\end{array}$ \\
\hline \multicolumn{4}{|l|}{ Types of discrepancies n (\%) } \\
\hline Clinical decision & $104(34.4)$ & $104(34.4)$ & - \\
\hline Clinical protocol & $84(27.8)$ & $84(27.8)$ & - \\
\hline Pharmacological alteration & $80(26.5)$ & $80(26.5)$ & - \\
\hline Non-standard medication & $34(11.3)$ & $34(11.3)$ & - \\
\hline Error due to omission & $300(80.9)$ & - & $300(80.9)$ \\
\hline Dose error & $23(6.2)$ & - & $23(6.2)$ \\
\hline Error due to action & $21(5.7)$ & - & $21(5.7)$ \\
\hline Use frequency error & $20(5.4)$ & - & $20(5.4)$ \\
\hline Different medication & $4(1.1)$ & - & $4(1.1)$ \\
\hline Dosage & $3(0.8)$ & - & $3(0.8)$ \\
\hline \multicolumn{4}{|l|}{ Medications involved n (\%) } \\
\hline A - Digestive tract and metabolism & $141(21.0)$ & $116(38.4)$ & $25(6.7)$ \\
\hline B - Blood and hematopoietic organs & $50(7.4)$ & $32(10.6)$ & $18(4.9)$ \\
\hline C - Cardiovascular System & $213(31.6)$ & $51(16.9)$ & $162(43.7)$ \\
\hline G - Genitourinary system and sex hormones & $8(1.2)$ & $3(1.0)$ & $5(1.3)$ \\
\hline H - Systemic hormonal preparations, excluding sex hormones and insulins & $27(4.0)$ & $12(4.0)$ & $15(4.0)$ \\
\hline J - Anti-infectives for systemic use & $5(0.7)$ & $3(1.0)$ & $2(0.5)$ \\
\hline L - Antineoplastic and immunomodulating agents & $6(0.9)$ & $4(1.3)$ & $2(0.5)$ \\
\hline M - Musculoskeletal system & $28(4.2)$ & $18(6.0)$ & $10(2.7)$ \\
\hline N - Nervous system & $158(23.5)$ & $50(16.6)$ & $108(29.1)$ \\
\hline R - Respiratory tract & $24(3.6)$ & $6(2.0)$ & $18(4.9)$ \\
\hline S - Sensitive organs & $3(0.4)$ & - & $3(0.8)$ \\
\hline V-Several & $10(1.5)$ & $7(2.3)$ & $3(0.8)$ \\
\hline \multicolumn{4}{|l|}{ Acceptance of interventions $n(\%)$} \\
\hline Intervention accepted & $110(30.6)$ & - & $110(30.6)$ \\
\hline Intervention not accepted & $128(35.7)$ & - & $128(35.7)$ \\
\hline Intervention not accepted - patient was hospitalized for less than 48 hours after intervention & $121(33.7)$ & - & $121(33.7)$ \\
\hline
\end{tabular}

Other studies have shown the identification mainly of justified discrepancies. In his study carried out in a hematology and oncology unit, Lindenmeyer ${ }^{22}$ observed that only $17.7 \%$ of the discrepancies were unjustified. Another study by Magalhães ${ }^{16}$ found that $21.4 \%$ of the medications had unjustified discrepancies, and these medication errors reached $31.8 \%$ of the patients. This demonstrates that the relationship found between justified and unjustified discrepancies varies greatly among studies: this can be explained by having different populations and different criteria to characterize the discrepancies.

The qualitative analysis of the unjustified discrepancies showed that the errors by default were the most frequent, followed by dose, action, and frequency of use. Similar studies corroborate this result, especially with regard to the higher incidence of discrepancies due to omission ${ }^{16,19,20,23}$. Omission of the medication at the time of admission can cause treatment discontinuation and, therefore, harms to the patient ${ }^{24}$. The lack of communication, or incomplete or inaccurate information at the time of the transition, can justify the fact that there is a greater number of errors by default.

When the causes that determined the justified discrepancies were analyzed, it was verified that the most frequent cause of discrepancy was a clinical decision, followed by a clinical protocol and by pharmacological alteration. It is well documented that some drugs can be replaced, discontinued or administered by another route, in the pre-surgical period, to reduce the risk of post-surgical complications or to reduce the possible risk of drug interactions.
Oral hypoglycemic agents, anticoagulants, and antithrombotics are examples of some of these drugs ${ }^{17}$. In this study, the findings related to the medications involved in the justified discrepancies are in agreement with the most frequent previous diseases in the population in question.

The drugs involved in the unjustified discrepancies were mostly those that act at the level of the cardiovascular system, followed by the nervous system and by the digestive and metabolic system. These results are consistent with studies carried out by other authors ${ }^{16,25}$. In a study carried out by Buckley et al. ${ }^{23}$, they identified that, among the discrepancies considered with potential serious clinical consequences, the majority covered cardiovascular agents (38.9\%).

Upon finding the unjustified discrepancy and a subsequent pharmaceutical intervention, it was verified that only 110 (30.6\%) of the interventions were accepted, reaching the goal of reconciliation, which is to avoid or minimize medication errors. Other published studies also show a predominance of non-acceptance of interventions, as in the case of Bezerra ${ }^{18}$, conducted with surgical patients in a hospital in the state of Sergipe, where only $14.2 \%$ of the interventions were accepted, and in the work developed by Lindenmeyer et al..$^{22}$ in an onco-hematological unit where it was identified that, only in $35 \%$ of the cases, the problem was resolved after the intervention. On the other hand, there are studies developed that show that, in the vast majority of times, there was acceptance of the approach with a relevant percentage, as in the studies carried out by Nascimento ${ }^{14}$ 
and Reis ${ }^{15}$ who showed an acceptance of interventions of $92.6 \%$ and $74.71 \%$, respectively. Similar data were also found in a study carried out by Mendes ${ }^{19}$ in a medical clinic unit of a university hospital in the state of Paraná, with acceptance by the medical team of approximately $75 \%$ of the interventions.

One possible reason for the results found in the present study, such as the low acceptance of the pharmaceutical interventions by the prescribing physicians, is the fact that there is not enough time to correct the prescription, especially in orthopedic cases where a high turnover of patients was perceived since, in 35.6\% (121) of the interventions performed, the patient was discharged, was transferred or died in less than 48 hours after the pharmaceutical intervention or, still, the resistance of some members of the multidisciplinary team.

In this study, some limitations must be considered, such as the fact that a large percentage of the patients admitted to the study units came from the Emergency Service (ES). It would be ideal to implement a reconciliation process at the point of entry of patients to the hospital, and not just in the wards. Still, due to the limitation of follow-up loss immediately after the pharmaceutical intervention, related to the transfer of patients from the unit, hospital or hospital discharge, it is not possible to absolutely measure the impact of the interventions.

\section{Conclusion}

It was verified that medication errors related to reconciliation occur in patients from the orthopedics and neurology specialties, but that they can be identified and resolved through the medication reconciliation process carried out by the clinical pharmacy service. The significant number of discrepancies identified represents an important opportunity to improve reconciliation in the sectors studied. When the pharmaceutical interventions were accepted, corrections of medication errors prevented possible adverse events for the patients, showing the importance of this service in the institution. This process allows the hospital clinical pharmacist to more actively participate in the therapeutic treatment, and the different health care providers to ensure better safety in the treatment of the patient, minimizing errors associated with the medication.

\section{Funding sources}

The author Cássia Regina Eidelwein was an intern in a hospital pharmacy, receiving a scholarship in the years 2017 to 2019.

\section{Collaborators}

CRE: development, preparation, interpretation of the article's data, and responsibility for all the information of the paper, ensuring the accuracy and integrity of any of its parts. CRE: guidance in the preparation, review of the data collected, review of the manuscript's content, and responsibility for all the information of the paper, ensuring the accuracy and integrity of any of its parts. LFC: analysis, review of the manuscript, and responsibility for all the information of the paper, ensuring the accuracy and integrity of any of its parts.

\section{Conflict of interests statement}

The authors declare that there are no conflicts of interest in relation to this article.

\section{References}

1. Aspden $\mathrm{P}$, Wolcott J, Bootman JL, et al. Preventing medication errors. Quality chasm series. Washington (DC), The National Academies Press. 2007; 480.

2. Fernandes $\mathrm{O}$. Medication reconciliation in the hospital: what, why, where, when, who and how?. Healthc Q. 2012; 15:42-49.

3. Anacleto TA, Rosa MB, Neiva HM, et al. Erros de medicação Farmácia hospitalar. Pharm Bras. 2010;1-24.

4. Moriel MC, Pardo J, Catalá RM, et al. Prospective study on conciliation of medication in orthopaedic patients. Farm Hosp. 2008; 32(2):65-70.

5. Mueller SK, Sponsler KC, Kripalani S, et al. Hospital-based medication reconciliation practices: a systematic review. Arch Intern Med. 2012; 172(14):1057-69.

6. Cornish PL, Knowles SR, Marchesano R, et al. Unintended medication discrepancies at the time of hospital admission. Arch Intern Med. 2005; 165(4):424-429.

7. Gizzi LA, Slain D, Hare JT, et al. Assessment of a Safety Enhancement to the Hospital Medication Reconciliation Process for Elderly Patients. Am J Geriatr Pharmacother. 2010; 8(2):127-135.

8. Pippins JR, Gandhi TK, Hamann C, et al. Classifying and predicting errors of inpatient medication reconciliation. J Gen Intern Med. 2008; 23(9):1414-1422.

9. Breves I. Conciliação medicamentosa: estratégia para evitar erros de medicação e aumentar a segurança do paciente, 2015. Available in: https://proqualis.net/entrevista/concilia\%C3\%A7\%C3\%A3o-medicamentosa-estrat\%C3\%A9gia-para-evitar-erros-de-medica\%C3\%A7\%C3\%A3o-e-aumentar-seguran\%C3\%A7a. Accessed on: November 26, 2018.

10. Gleason KM, Brake $H$, Agramonte $V$, et al. Medications at Transitions and Clinical Handoffs (MATCH) Toolkit for Medication Reconciliation. (Prepared by the Island Peer Review Organization, Inc., under Contract No. HHSA2902009000 13C.) AHRQ Publication No. 11(12)- 0059. Rockville, MD: Agency for Healthcare Research and Quality. Revised August 2012.

11. Lombardi NF, Mendes AEM, Lucchetta RC, et al. Análise das discrepâncias encontradas durante a conciliação medicamentosa na admissão de pacientes em unidades de cardiologia: um estudo descritivo. Rev. Latino-Am. Nursing. 2016; 24:e2760.

12. World Health Organization [WHO]. Collaborating Centre for Drug Statistics Methodology, Guidelines for ATC classification and DDD assignment 2013. WHO Collaborating Centre for Drug Statistics Methodology. 2012: 284.

13. Sanchéz OD, López IM, Monjo MC, et al. Conciliación de la medicación: assumamos la responsabilidad compartida. Farm Hosp. 2008; 32(2):63-4.

14. Nascimento AA. Avaliação da conciliação medicamentosa em um hospital universitário [Trabalho de conclusão de curso]. Universidade Federal da Paraíba. João Pessoa - PB, 2017.

15. Reis WCT, Scopel CT, Correr CJ, et al. Análise das intervenções de farmacêuticos clínicos em um hospital de ensino terciário no Brasil. Rev. Einstein. 2013; 11(2):190-196. 
16. Magalhães GF. Conciliação medicamentosa em pacientes de um Hospital Universitário [Dissertação]. Universidade Federal da Bahia, Salvador, 2017.

17. Domingos SCF. Discrepâncias na medicação e reconciliação terapêutica em doentes internados: uma avaliação descritiva [Dissertação]. Faculdade de Farmácia da Universidade de Lisboa, Lisboa, 2013.

18. Bezerra CSLF. Reconciliação medicamentosa em pacientes cirúrgicos em um hospital do estado de Sergipe [Dissertação] Universidade Federal de Sergipe, São Cristóvão - SE, 2015.

19. Mendes AEM. Conciliação de medicamentos na admissão hospitalar: um ensaio clínico randomizado [Dissertação]. Universidade Federal do Paraná, Curitiba - PR, 2016.

20. Marzal-Alfaro B, Raque AL, Sánchez G, et al. Errores de medicación en un servicio de urgencias según el consenso español de conciliación de la medicación. Rev Bras Farm Hosp Serv Saúde. 2015; 6(2):6-11.

21. Tam VC, Knowles SR, Cornish PL, et al. Frequency, type and clinical importance of medication history errors at admission to hospital: a systematic review. Can Med Assoc J. 2005; 173(5):510-515.

22. Lindenmeyer, LP, Goulart VP, Hegele V. Reconciliação medicamentosa como estratégia para a segurança do paciente oncológico- resultados de um estudo piloto. Revista RBFHSS. 2013; 4(4):51-55.

23. Buckley MS, Harinstein LM, Clark KB, et al. Impact of a Clinical Pharmacy Admission Medication Reconciliation Program on Medication Errors in 'High-Risk' Patients. Ann Pharmacother. 2013; 47(12):1599-1610

24. Gleason KM, McDaniel MR, Feinglass J, et al. Results of the Medications at Transitions and Clinical Handoffs (MATCH) study: an analysis of medication reconciliation errors and risk factors at hospital admission. J Gen Intern Med. 2010; 25(5):441-447.

25. Gleason KM, Groszek JM, Sullivan C, et al. Reconciliation of discrepancies in medication histories and admission orders of newly hospitalized patients. Am J Health Syst Phar. 2004; 61 (16):1689-1695 